\title{
RETRACTED ARTICLE: Cold Nuclear Fusion explained by hydrogen embrittlement and piezonuclear fissions in the metallic electrodes-Part I: $\mathrm{Ni}-\mathrm{Fe}$ and $\mathrm{Co}-\mathrm{Cr}$ electrodes
}

\author{
A. Carpinteri · O. Borla $\cdot$ A. Goi $\cdot$ A. Manuello $\cdot$ \\ D. Veneziano
}

Received: 4 December 2013/ Accepted: 14 June 2014/Published online: 23 July 2014

(C) Springer Science+Business Media Dordrecht 2014

This article has been withdrawn by the Publisher and the Society in agreement with the Editor-in-Chief due to conflict of interest reasons. In a commitment to scientific integrity we decided to withdraw the article as the editorial process had been compromised.

A. Carpinteri $(\bowtie) \cdot$ O. Borla · A. Goi ·

A. Manuello · D. Veneziano Department of Structural, Geotechnical and Building Engineering, Politecnico di Torino, Corso Duca degli Abruzzi 24, 10129 Turin, Italy e-mail: alberto.carpinteri@polito.it

A. Manuello e-mail: amedeo.manuellobertetto@polito.it 